\title{
La pérdida de la memoria histórica: a cien años de la Primera Guerra Mundial ${ }^{1}$
}

\section{The Loss of Historical Memory: 100 Years of the First World War} A perda da memória histórica: 100 anos da Primeira Guerra Mundial

\author{
Grace Prada-Ortiz \\ Instituto de Estudios Latinoamericanos \\ Universidad Nacional de Costa Rica \\ Recibido 15/08/2014 • Aprobado 10/10/2014 \\ DOI: http://dx.doi.org/10.15359/tdna.31-57.5
}

mucho que decir en torno a la guerra y la paz. A cien años de conmemorar el estallido de la Primera Guerra Mundial, este ensayo ofrece consideraciones desde las ciencias históricas, y también desde el sentimiento, sobre la guerra como proceso destructor de vida cuyo anclaje es el expansionismo de las potencias y del capital financiero por el control de recursos y la acumulación de riquezas.

Palabras claves: Primera Guerra Mundial, Centroamérica, derecho a la autodeterminación de los pueblos, mujeres, Temas de Nuestra América.

Dar vida está estrechamente vinculado con la madre y el poder de las mujeres, es por ello que las mujeres tenemos

\section{Absract}

Giving life is closely linked to motherhood and female power. That's why women have so much

1 Conferencia dictada en la UNILA, Bogotá, Colombia.

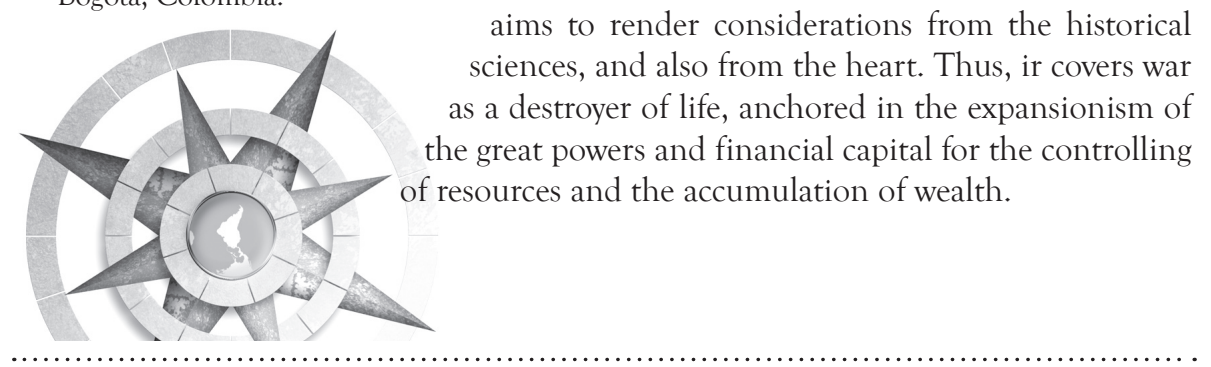
to say about war and peace. A hundred years after the outbreak of the First World War, this essay aims to render considerations from the historical sciences, and also from the heart. Thus, ir covers war as a destroyer of life, anchored in the expansionism of 
Keywords: First World War, Central America, Peoples' right to self-determination, women, Temas de Nuestra América

\section{Resumo}

Dar vida está estreitamente ligado à maternidade e poder das mulheres, é por isso que ao mulheres temos muito a dizer sobre guerra e a paz. Cem anos após a eclosão a Primeira Guerra Mundial, este ensaio apresenta considerações a partir das ciências históricas, mais também a partir do sentimento. Assim, abarca-se a guerra como um destruidor de vida, cuja ancoragem é o expansionismo das potências e do capital financeiro em sua avareza pelo controle dos recursos e da acumulação de riqueza.

Palavras-chave: Primeira Guerra Mundial, América Central, direito à auto-determinação, mulheres, Temas de Nuestra América

En el arduo y minucioso trabajo de arqueologizar el conocimiento desde la perspectiva histórica y de género, sin duda alguna, el abordaje del tema de las guerras es una de las tareas más crudas y difíciles. No hay nada que celebrar, solamente recordar la pérdida innecesaria de vidas humanas que tuvieron sueños de paz, esperanza, amor y libertad.

Con intensa pasión, miles de jóvenes soldados y sus familias vivieron la llamada Gran Guerra, con la esperanza de construir sociedades justas, libres y equitativas. Nada más cruel que recordar los hechos históricos que mutilaron muchas vidas y cercenaron los sueños de jóvenes hombres y mujeres; de las madres, hermanas, novias, esposas, amigas y amantes que los esperaban. Los que tuvieron un poco más de suerte regresaron, aunque mutilados por ese denominado servicio a la patria, que los mandó a una guerra cuerpo a cuerpo sin tiquete de regreso seguro.

Cuando recibí la invitación a reflexionar sobre este evento pensé ¿qué será lo que tengo que decir acerca de una guerra sobre la cual ha corrido tanta tinta cuando más bien quiero olvidar las siguientes hasta el día de hoy.

Al iniciar la escritura de este texto creí que debía pedir disculpas por mi sensibilidad y el tono coloquial de mi discurso. Sin embargo, pensándolo mejor, creo que las disculpas no son necesarias y que, más bien, debo dar gracias a la vida, como dice la bella canción de Violeta Parra, de que «la guerra no me sea indiferente», como cantaba Mercedes Sosa. Así, pues, le doy gracias a la vida de que mi humanidad todavía esté intacta.

Tengo atragantado el genocidio sionista contemporáneo de Palestina. Y el corazón hecho un puño de dolor por el dolor ajeno: me estremece, hasta lo más recóndito de mi alma, saber que acabo de estar jugando con

84 La pérdida de la memoria histórica: a cien años de ... Grace Prada Ortiz

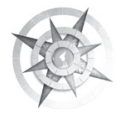


mi hermosa nieta, mientras tantas madres, abuelas, padres -seres humanos de otras latitudes- entierran a sus niños y niñas gracias a las guerras del siglo XXI. Sinceramente, soñaba con un nuevo siglo menos sangriento que los anteriores. ¡Ingenua mujer!, me digo en silencio, esto no será posible hasta que el expansionismo y el capital financiero no se instalen en las todas las regiones del mundo donde puedan extraer petróleo, gas y minerales para continuar con la industria de la guerra y la acumulación de la riqueza en pocas manos.

De pronto, sin tener conciencia clara de cuál sería mi punto de partida para este escrito, meencontrésentada imaginando los horrores de aquella guerra, infame como todas. Casi escuchaba detonar los cañones y visualicé rostros de jóvenes soldados con uniformes ajados y roídos por el tiempo, enfrentándose ferozmente entre sí a punta de bayonetas; el silbido de los primeros avioncitos de guerra chillaban dolorosamente en mis oídos, los charcos de sangre por un momento cegaron mi pensamiento. Por un instante vi a muchos hombres, que antes no se conocían, matándose en una encarnizada lucha sin cuartel, los gritos de dolor se amontonaron en mi mente: brazos rotos, piernas sueltas tiradas, cascos retorcidos, pechos destrozados por las cuchillas de las bayonetas, cuerpos mutilados en el lodo como si la vida no tuviese ningún valor.

Los gritos desgarradores sonaban al unísono en diferentes idiomas. Los costales de arena de los frentes de batalla no eran suficiente refugio, uno tras otro caían ensangrentados, gritando de dolor y muriendo en soledad sin nadie que cerrara sus ojos; aquellos hombres que tiempo atrás fueron los crisoles de tantas madres que nunca pensaron que dar vida pudiera eso: que sus retoños murieran de forma despiadada.

Recorrí con la memoria aquellos campos helados y ensangrentados, llenos de huesos rotos, recogiendo fotos, cartas, pedazos de cabello, medallas, anillos de bodas, anillos de mujeres, zapatitos de niños, relicarios con fotos de amores, una cinta de cabello femenina, todo lo que simbolizara el más profundo y sincero amor de humanos $y$, por qué no decirlo, si la imaginación es tan cierta como la realidad misma, miles y miles de pedazos de almas desperdigadas en tierras desconocidas y que buscaban cómo retornar a sus cuerpos ya inertes.

Todos esos restos los eché en una inmensa bolsa de amor y los fui guardando en mi memoria femenina, para nunca olvidar a quienes abonaron las tierras de combate con su propia sangre. 
Recordaba el intenso frío de la Europa del año 1914 en otoño e invierno, escuchaba chasquear los dientes de los hombres a quienes el frío helaba hasta el tuétano; pieles resecas que habían cambiado de un sano color sonrosado a uno que hacía juego con las cenizas del suelo. Respiré con pesadez y con dolor en el pecho. Por un momento sentí un olor a carne quemada y el hedor que antecede a la muerte en los campos de batalla. Me pareció escuchar voces que venían de un pozo no lejano: «QQué diablos hace aquí? ¿Por qué nos trae a colación cien años después? ¿Qué pretende con su morbo, señora del siglo XXI? »

¡Mis Diosas! -Pensé- ya del todo estoy loca recreando el dolor de otros tiempos y que siento en carne propia ¿Qué cosa es esta? Sin mucho divagar pensé iseré la madre de todas aquellas almas que cayeron en combate o estaré pensado lo que las mujeres de esos hombres sintieron en aquellos tiempos? Obviamente lo primero no es; tal vez lo segundo sí, porque el dolor de las madres no tiene fronteras, espacio ni tiempo.

Retomé mi diálogo interno y les dije: «disculpen mis amados soldados, no es mi intención hacerles el menor ruido, pero sí recordarle a las nuevas generaciones que la muerte prematura de los soldados en la llamada Gran
Guerra no cambió el mundo como los soñadores pensamos, solo incrementó las pingües ganancias y riquezas de quienes lucran con las guerras y no ponen ningún muerto». Soldados a quienes agobiaban el hambre, la sed, el frío, el desvelo y el dolor físico y emocional. El alma salía y entraba de sus cuerpos como tratando de darles tregua para continuar en aquellos infames combates de una guerra que no era de ellos, para quienes la única compañía segura era la soledad y la parca que asediaba cada día para tomar las vidas jóvenes de los soldados.

Los gases tóxicos derramados como experimentos siniestros se transformaban en nubes inmensas que flotaban hacia el aire, formando figuras diversas que quedarían atrapadas por siempre en la atmósfera. Las otrora tierras fértiles se fueron oscureciendo hasta transformarse en cenizas donde por mucho tiempo no fue posible que retornara una flor ni brotara el trigo que daría de comer a la humanidad, en donde no pastaba el ganado y, en la de menos, las gallinas en vez de huevos pondrían balas. ¡Solo eso nos faltaba! -Pensé-.

Cuantas enfermedades extrañas y temibles no habrán sido engendros creados en laboratorios químicos para la destrucción de la humanidad. Cuando los creyentes me hablan de la llegada del 
Apocalipsisguardosilenciodependiendo del grado de fundamentalismo de mi interlocutor. La verdad es que no necesitamos más dramas de apocalipsis: ya los ha creado el ser humano; no son necesarios los jinetes que vienen del cielo, hay gran cantidad de infelices y mercenarios al servicio de la industria de la guerra haciendo experimentos para el exterminio masivo. Así se hizo el gas cloro, el gas mostaza y el Agente Naranja, entre otros químicos utilizados como armas de exterminio masivo.

\section{Como mujer y madre no perdono las guerras}

En mi juventud, siendo estudiante universitaria, sin mayor conocimiento de la teoría feminista, me dije muchas veces si somos las mujeres las que parimos, el asunto de las malditas guerras se acabaría el día en el que las mujeres hiciéramos una «huelga mundial de piernas cerradas» y no pariéramos más retoños para que los dueños de las guerras no se hicieran más ricos con la muerte de los hijos de las clases trabajadoras. Ciertamente una medida muy radical de castidad impuesta para acabar las guerras ¡Utopía versus realidad, me digo ahora! Leyendo sobre feminismo y las posturas respecto a las guerras encontré que mi idea no era tan loca; ya otras mujeres, seguramente desquiciadas de dolor por haber perdido a sus hijos, esposos, padres, hermanos, amantes, es decir a los hombres de sus vidas, con anterioridad habían pensado lo mismo.

Las mujeres somos dadoras de vida y este privilegio, en principio, nos debe humanizar más. Es por ello que mi lectura de la historia y la vida cotidiana tiene un matiz un tanto diferente. Plenamente consciente de que la maternidad debe ser una opción, no una imposición, dar vida es un privilegio exclusivamente femenino, cuando así lo decidimos, valga la aclaración. Dar la vida a un ser humano es un acto heroico y no tiene nada que ver con el romanticismo barato que nos venden para las celebraciones del día de la madre. Dar vida está estrechamente vinculado con la madre y el poder de las mujeres, es por ello que las mujeres tenemos mucho que decir en torno a la guerra y la paz. El patriarcado ha definido la patria como femenina -como símbolo de debilidad femenina-, por eso hay que someterla o defenderla hasta las últimas consecuencias. Eso hicieron los soldados de la Gran Guerra, y lo han seguido haciendo en las guerras de la actualidad. Aun cuando las guerras en tiempos de globalización tienen otros matices que analizar.

Al recrear mi propia maternidad es imposible dejar de pensar en todas las madres que perdieron a sus hijos en la Gran Guerra. Haciendo un rápido

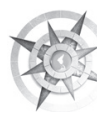


recuento realmente es posible afirmar que son pocos los momentos de paz que ha vivido la humanidad. En estos cien años de historia el inventario de vidas perdidas es alarmante y da pocas esperanzas de un mundo pacífico, sin guerras. Así lo demuestran los últimos acontecimientos en la Franja de Gaza, en Palestina.

Soy originaria de un país sin tradición bélica, que abolió el ejército el 1 de diciembre de 1948, lo cual no quiere decir que no existan conflictos sociales. Pero ninguna madre costarricense sabe lo que es mandar a un hijo al frente de batalla, en ese sentido somos dichosas. Hasta aquí mi paréntesis coloquial y humano del sentir de una madre del siglo XXI sobre la Gran Guerra.

Desde un punto de vista histórico e intelectual, es necesario indicar que muchas historiadoras e historiadores coincidimos en que la primera guerra de carácter imperialista se dio en Nuestra América, para utilizar el término de Martí a lo que hoy conocemos como América Latina.

La recién emancipada Cuba en 1895, fue el principal botín de la guerra hispanoamericana de 1898, sucedida entre dos imperios a los que no les pertenecían las tierras de Nuestra América.
De un lado estaba el Imperio español con una economía devastada y la pérdida de la mayoría de sus colonias como producto de un proceso de emancipación y liberación antiespañolista que tuvo su despegue en las luchas antiesclavistas de 1804 en Haití. Tal proceso estuvo encabezado por Toussaint Louverture, un general negro que, durante las guerras entre Gran Bretaña, España y Francia, participó con los españoles y los franceses con el fin de expulsar a los británicos de la isla. Y en el otro flanco la emergente nación de los Estados Unidos de América, rapaz y con su modelo expansionista en apogeo.

Estos acontecimientos los denomino, como en un ensayo anterior, el despegue de la liberación imperialista en tierras haitianas. Con la sublevación de esclavos, luego de varias batallas y estrategias militares, la expulsión de los británicos de la isla se hizo efectiva a mediados de 1798 .

Las hostilidades entre los mulatos y los esclavos continuaron. Jean Jacques Dessalines y Henri Christophe se unieron a Louverture contra las tropas francesas de Napoleón. Al mando del general Charles-VictorEmmanuel Leclerc se reconquistó la isla para los franceses. Louverture fue capturado en 1802, enviado a Francia y enjuiciado por Napoleón. 
Al morir Louverture en Besanson en 1803, su lugar como general de las tropas rebeldes antiesclavistas lo tomó Dessalines, quien derrotó a los franceses en la sangrienta Batalla de Vertieres y proclamó la independencia de Haití el primero de enero de 1804.

La chispa iniciada en Haití sopló con fuerza y se trasladó a tierra firme, donde continuaron las luchas emancipatorias en la Nueva España (México) y el sur de la América Española. Los diferentes procesos de rebelión y emancipación política se tornaron más o menos beligerantes, dependiendo de la zona de conflicto en Hispanoamérica. En Nueva España y los virreinatos del sur de América los enfrentamientos bélicos entre españoles y antirealistas fueron de magnitudes importantes. Mientras que en la región de la Capitanía General de Guatemala casi recibimos por decreto la independencia de la Corona española, amén de uno que otro evento de resistencia que se dio en algunos sectores sociales de $\mathrm{El}$ Salvador, Nicaragua y Guatemala, organizados, prioritariamente, por los criollos, terratenientes e intelectuales antiespañolistas. La lejanía de las zonas de conflicto armado de alguna forma nos mantuvo aislados de los procesos macro de emancipación de la América hispana.
España, potencia imperial en decadencia, necesitaba recuperar el poder y el espacio perdidos como producto de la emancipación política de las colonias en América. El emergente imperialismo de los Estados Unidos de América hizo su aparición en la escena política, territorial e ideológica del mundo con sendas declaraciones doctrinales sobre sus supuestos derechos en razón de su vecindad con las recién emancipadas naciones que se aprestaban a la consolidación de las Repúblicas y a formar sus Estados-naciones.

Estados Unidos -desde la declaración de la Doctrina Monroe en 1823, el Destino Manifiesto, la «Enmienda Platt» en 1901 y sus subsiguientes doctrinas de carácter expansionistahabía preparado el terreno financiero y político para apropiarse de las otras colonias españolas a través de inversiones de capital en la industria azucarera de Cuba y facilitándole empréstitos a la Corona española. Acertadamente, Alejandro de Humboldt llamó a la Perla del Caribe la «isla del azúcar y de los esclavos» (citado por Guerra, 1964, p. 7).

Las inversiones extranjeras en productos agrícolas de gran importancia para la exportación fueron creciendo y puede afirmarse que se crearon las condiciones materiales para una guerra entre una potencia en estado 
de coma y un vigoroso imperio que buscaba apoderarse de gran parte del entonces decrépito Imperio español. De esta manera, como resultado de la guerra hispanoamericana, que duró menos de cuatro meses (del 25 de abril al 12 de agosto de 1898) y cuyo escenario fue el mar Caribe y el océano Pacífico, se marcó el inicio del fin del Imperio español y el inicio de la dominación imperialista de los Estados Unidos sobre toda la región de Nuestra América.

Cuba pasó a ser protectorado de los Estados Unidos, entre otros otros territorios (Guam, Puerto Rico y las Filipinas) que España tuvo que ceder por veinte millones de dólares. De esta forma, España perdió el control político y sus últimos colonias en Hispanoamérica. Y este fue el inicio de muchas más guerras imperialistas en el mundo, que, entre otras cosas, han facilitado el reparto de territorios entre los países imperialistas de Alemania, Inglaterra y Francia, durante el siglo XVIII, XIX y principios del XX. España, Portugal y la Rusia zarista no calificaban como imperios con gran cantidad de inversiones en sus zonas de influencia.

Desde esa otra región del mundo, el campesinado ruso moría de hambre por el derroche de su dinastía real y por la carencia de tierras para cultivar. La eclosión de los movimientos sociales no se hizo esperar, el fiasco protagonizado por el zarismo y su política sangrienta tuvo un gran impacto en los acontecimientos de la Primera Guerra Mundial. En medio de severos conflictos sociales la Revolución de Octubre de 1917, más conocida como la Revolución Bolchevique, le dio un giro inesperado a los acontecimientos de la Gran Guerra. El Gobierno zarista fue derrocado por las fuerzas revolucionarias y, al tomar el poder la Revolución Bolchevique, una de las primeras medidas fue salirse de una guerra que no tenía que ver con las necesidades y prioridades del gobierno del proletariado ruso.

Con este panorama dio inicio una guerra tan injusta como otra cualquiera, en la que los muertos los ha puesto siempre el pueblo, es decir, la clase obrera.

Valga decir que desde la visión política de Lenin, a quien le tocó vivir todo el proceso de la Primera Guerra y el dominio zarista, así como ser el líder de la Revolución Bolchevique, las guerras se pueden definir como justas e injustas. Su crítica al nuevo reparto mundial de los países y la lucha entre las potencias imperiales que añoraban conquistar el mundo a través de las estrategias de mercado, las inversiones de grandes capitales

90 La pérdida de la memoria histórica: a cien años de ... Grace Prada Ortiz 
financieros y el sometimiento de otros pueblos lo llevó a realizar una fuerte crítica en la Segunda Internacional acerca de la teoría burguesa de la guerra defensiva o la defensa de la patria: "La defensa de la patria es una mentira en la guerra imperialista, pero no es de ninguna manera una mentira en una guerra democrática y revolucionaria» (Lenin, 1973: p. 4).

En su afán por el cambio revolucionario, Lenin asumió que las guerras son justas en la medida en que se lucha contra los opresores y esclavizadores de los pueblos. Es importante no sacar de contexto esta afirmación de Lenin; sin embargo, en la actualidad la teoría de las guerras justas, como estrategia para erradicar formas de opresión, es bastante debatible, asunto sobre el cual no pretendo profundizar en este momento.

El asunto de fondo, desde mi posición epistemológica, política $y$, por supuesto, ideológica, es quién pone las armas y quién pone los muertos. Sin duda alguna, aún en pleno siglo XXI los muertos no son precisamente los hijos de las clases privilegiadas de los países que promueven las guerras y menos las hijas y los hijos de quienes hacen de la guerra su modus vivendi. Profundizando más, se trata de la ética de las guerras y de quienes se hacen megamillonarios con la carrera armamentista que iniciaron las fuerzas beligerantes que participaron en las contiendas bélicas de la Primera y Segunda Guerras Mundiales oficialmente declaradas, y todos los conflictos bélicos que venimos viviendo desde el fin de la Segunda Guerra Mundial.

La Primera Guerra Mundial (19141918) debe ser entendida como una guerra imperialista en la que participaron tres grupos bélicos bien definidos, cada uno de ellos con sus propios intereses económicos y militares y sus ambiciones de expansión territorial. El primer bloque bélico estuvo conformado por Alemania, Austria-Hungría, Turquía y Bulgaria. El segundo bloque lo integraron Rusia, Francia, Inglaterra, Bélgica, que había sido invadida por los alemanes, e Italia, que posteriormente dejaría a la Triple Alianza al ser traicionada por Alemania, que en su momento apoyó las pretensiones austriacas en Los Balcanes. Y el tercer bloque lo integraron Estados Unidos y Japón.

Es necesario destacar que, antes de la consolidación de los bloques beligerantes que protagonizaron la Primera Guerra Mundial, las relaciones diplomáticas e internacionales por el nuevo reparto del mundo realizado por las grandes potencias imperialistas, no 
era del agrado de prácticamente ninguno de ellos. La exagerada política de expansionismo territorial de los países más grandes fue creando focos de tensión que, finalmente, detonaron como las causas del conflicto armado denominado Primera Guerra Mundial o Gran Guerra. Desde el punto de vista metodológico se pueden identificar dos grandes nodos que dieron como resultado dichas causas:

1. El primer nodo, y el más relevante por sus implicaciones, lo constituye lo que llamo la redefinición de una nueva economía de mercado transnacionaly un capital financieroindustrial que se caracterizó por los siguientes rasgos:

- La expansión económica, el control de los mercados coloniales, la inversión de capitales en las economías dependientes y periféricas, el urgente desarrollo y la exportación de la industria europea

- La competencia por el control de las esferas de influencia comercial entre Inglaterra y Alemania y Francia por las colonias

2. El segundo nodo está directamente relacionado con el control de territorios dotados de recursos naturales, muy importantes para la producción de pertrechos en la carrera armamentista que daba sus primeros pasos. Este nodo se caracterizó por los siguientes aspectos:

- Las diferencias y contradicciones generadas por el reparto de los territorios de las otras colonias imperiales

- Las fricciones y tensiones políticas entre Alemania y Francia por los resultados de la Guerra Franco-Prusiana

- El conflicto latente entre Rusia y Austria por el control de Los Balcanes

- Los conflictos políticos entre Inglaterra, Francia y Rusia por las desigualdades en el reparto de los territorios coloniales fueron dejados de lado para dar paso a la configuración de alianzas internacionales, que protagonizaron la Primera Guerra Mundial.

Ambos nodos, con sus respectivos rasgos y características tanto de orden económico como político, diplomático y hasta militar, pueden considerarse las principales causas del conflicto entre las potencias imperiales durante la Primera Guerra Mundial. 
El asesinato del archiduque Francisco Fernando, heredero de la Corona austriaca, en Sarajevo, el 28 de junio de 1914, fue el pretexto perfecto que necesitaban las potencias imperiales para entrar en la aventura de aquella primera contienda bélica mundial. Cada bloque aprovechó la coyuntura para declararle la guerra al otro, de esta manera se fraguó una de las guerras más sangrientas de la historia de la humanidad, que hoy recordamos por cumplir cien años de ignominia. Así que repito: no hay nada que celebrar sobre la historia de la Primera Guerra Mundial. Los datos nos dicen que el número de muertos en esta conflagración fue, aproximadamente, de nueve millones de personas, entre civiles y militares, y la cantidad de heridos se estimó en unos treinta millones, también contando civiles y militares.

Ahora bien, ¿qué pasó en la verde y pequeña Centroamérica durante la Primera Guerra Mundial? ¿Cómo impactó este acontecimiento de gran magnitud en la vida de cada uno de los países centroamericanos?

Los países centroamericanos en la primera década de siglo XX apenas se encontraban en la etapa de consolidación de los Estados-nación. No tenían ni un siglo de emancipación política de España cuando la mayoría de ellos quedaron bajo el control de los Estados Unidos de América, la potencia ganadora de la primera guerra imperialista como lo he mencionado anteriormente. Así las cosas, desde su estatus de potencia imperial, Estados Unidos utilizó los más diversos -y perversos métodos para iniciar su expansionismo y anexarse tierras de México y del Caribe. La diplomacia estadounidense se aseguró de garantizar los mecanismos de legitimación de su expansionismo y para la anexión de muchos territorios, por ejemplo Florida occidental y oriental, quitada por la fuerza a España en 1810 y 1821, respectivamente; Luisiana, comprada a Francia en 1803; Texas, quitado por la fuerza a México, en lo que se denomin, anexión abierta, en 1845; Oregon, a expensas de España, 1846; Nuevo México y California, territorio obtenido de México en 1848; Alaska, comprada a Rusia en 1867; y otros territorios cedidos por Gran Bretaña (Ramiro, 1964).

Para ello Estados Unidos se armó diplomáticamente de «doctrinas» que lo respaldaron en su política expansionista ante la comunidad internacional, iniciando con la «Enmienda Platt» (1901), con la que obtuvo Puerto Rico y Guantánamo, pasando por la Doctrina Monroe (1823), que entre sus cláusulas indica "América para los Americanos». A partir de este momento $-\mathrm{y}$ con las 
subsiguientes doctrinas: la del Gran Garrote, las de Seguridad Nacional y la Doctrina del Terrorismo, del 11 de setiembre de 2001- los Estados Unidos se autodeclararon los policías del mundo entero.

El periodo que va de 1903 a 1933 es conocido en la historia de América Latina como la era intervencionista. Haití, República Dominicana, Nicaragua y Panamá fueron los principales países que sufrieron intervención militar del ejército estadounidense.

Como se desprende de estos datos históricos, aun cuando los países centroamericanos no participaron directamente en los acontecimientos de la Primera Guerra Mundial, sirvieron de plataformas económicas, políticas y militares para garantizarle a los Estados Unidos la acumulación de capitales que eventualmente fueron usados en esta guerra política que contó con el apoyo de la mayoría de los gobiernos locales que seguían el modelo de economía dependiente. De esta forma, los gobiernos centroamericanos adquirieron empréstitos leoninos de la potencia estadounidense a cambio de las mejores tierras para la producción agrícola de banano y café. La época de la inversión extranjera, en la primera década del siglo XX, fue enorme en todos los países de la región. El conocido inversionista Minor Keith se asentó desde 1899 en las mejores tierras del sur de Costa Rica y fundó la United Fruit Company con un contrato de 99 años. El trato a los trabajadores agrícolas fue inhumano y trajo como consecuencia política el descontento, la creación de organizaciones sindicales y una de las más fuertes huelgas bananeras (1936).

La mayoría de los Gobiernos de turno de los países centroamericanos se obnubilaron con la inversión y abrieron las puertas al capital financiero de los Estados Unidos sin mayores condiciones, quedando comprometidos política, social, militar e ideológicamente hasta el presente. Facilitaron sus infraestructuras, los ferrocarriles y las vías marítimas para que las tropas estadounidenses, supuestamente neutrales -como en todas las guerras-, ocupasen territorios temporalmente con fines militares.

La artificial emancipación de Panamá, en 1903, dio como resultado la apertura de un canal interocéanico del cual el Gobierno de los Estados Unidos asumió el control absoluto, recogiendo por muchos años los réditos económicos que dejaba el tráfico por el Canal de Panamá.

En este estado de cosas, la mayoría de los países centroamericanos, con la economía de exportación, inmersos en las llamadas economías 
de postres o Bananas Republics, dependían de las posibilidades de exportar sus productos, para lo cual existían realmente pocas alternativas efectivas y rápidas. No fue hasta que llegaron los primeros frigoríficos que la exportación del banano se incrementó notablemente. Las primeras exportaciones de café de Costa Rica datan de 1820 y se dirigieron a Chile y Panamá, y posteriormente hacia Inglaterra.

Los migrantes alemanes que huían de las crisis europeas de principios de siglo XX se posicionaron en las mejores tierras cafetaleras de la Meseta Central de Costa Rica, entre 1902 y 1903, como en el caso de Otto Hube y Wilhemn Peters, quienes fundaron verdaderos emporios cafetaleros en Costa Rica, exportando hacia Europa, principalmente hacia Hamburgo. Posteriormente, de acuerdo con mi investigación, apoyaron a los nazis en la Segunda Guerra Mundial, escondiéndolos en el sótano de una casa de estilo victoriano, construida en 1903, que hoy es un museo. Estos datos son parte de la investigación que realicé sobre la hacienda La Caja en 1994.

Como economías dependientes de las exportaciones, y consumiendo todos los productos importados, el impacto de la Primera Guerra Mundial fue resentido en las economías locales. No tenían suficientes compradores para los productos agrícolas, por ende el desempleo se incrementó. La caída de los mercados y la drástica disminución del comercio con las potencias importadoras debilitaron notablemente a las frágiles economías centroamericanas.

Desde el punto de vista político, los esfuerzos por lograr la unidad centroamericana han sido acallados por los intereses locales y la ausencia de cohesión en un proyecto integrador de la región centroamericana. Desintegrados políticamente por rencillas políticas internas y dependientes de la inversión extranjera -léase estadounidense y británica-, con ninguna posibilidad de crear bloques políticos fuertes ni de defender la soberanía nacional, cada país de la región centroamericana se dedicó a tratar de organizarse política, económicamente e ideológicamente sobre la base del modelo liberal, heredado de las reformas liberales de 1870 .

Los conflictos internos de cada país llevaron a Nicaragua, Guatemala, El Salvador y Honduras a bregar con dictaduras militares las primeras tres décadas del siglo XX, impuestas por las burguesías que habían hecho alianzas económicas con los inversionistas extranjeros, comprometiendo seriamente la soberanía de los países de la región. El mayor impacto para los países centroamericanos fue de carácter económico: la falta de 
empleo y la caída de los precios de exportación del café y del banano.

El país que salió ganancioso y fortalecido de la Gran Guerra fue sin duda los Estados Unidos de América. La Gran Guerra le facilitó un creciente dominio de las finanzas internacionales, ya que logró acumular el $40 \%$ de las reservas de oro del mundo. Se convirtió en el nuevo acreedor de Europa. En esta correlación de fuerzas, con una nueva posición de acreedor financiero de alrededor de diez mil millones de dólares asumió su papel de potencia hegemónica para controlar los asuntos económicos, políticos y militares de todo el mundo, con el poder, incluso, para autodefinirse como los policías del mundo.

\section{Un corresponsal centroamericano} en la Primera Guerra mundial

El escritor guatemalteco Enrique Gómez-Carrillo es el único periodista centroamericano del que se tenga noticia, que actuó como corresponsal de guerra durante la Primera Guerra Mundial. Escribió desde el mismo frente de batalla. Su casa, en la capital frances, fue sede de la Asociación de Corresponsales Extranjeros.

De la lectura de sus crónicas, resalta la intención de trasladarnos la impresión de la guerra en todo su drama, pero siempre desde el punto de vista del ser humano individual, sin ocuparse tanto de los movimientos de los batallones o de los regimientos.

Narra, en una de sus crónicas titulada Campos de batalla y campos en ruinas (2014) detalles que a otros observadores podrían parecerle irrelevantes, como su paso por la población de Thann: «La mitad de las tiendas están cerradas. Las llamas han devorado multitud de casas. Para dormir tranquilos, al abrigo de las bombas, hay que refugiarse en los sótanos. Las calles se hallan casi desiertas. Los víveres cuestan caros»

El nuevo escenario de la guerra moderna son los núcleos urbanos. Para los ejércitos que se movilizan ese año de 1914, los nudos de carreteras, las estaciones de ferrocarril, las estaciones de radio, telégrafo y teléfono son objetivos estratégicos necesarios para el avance y la victoria. Los llanos despoblados dejan de tener valor estratégico. Una carretera, una colina fortificada, una línea de ferrocarril son ahora los imperativos por los que se lucha, y en este nuevo escenario la población civil, que vive en esos núcleos, se convierte en la gran víctima. Al escritor guatemalteco esta nueva situación no se le escapa:

Con la firma del Tratado de Versalles en 1919 los aliados dieron por sentado, en teoría, el fin de la Gran Guerra, que se pensó que sería

\section{La pérdida de la memoria histórica: a cien años de ... Grace Prada Ortiz}


la última. Pero los «señores de las guerras», quienes solo se encargaron de administrar el conflicto bélico, no tuvieron el tino de prever que, con las condiciones impuestas a Alemania tanto en términos económicos como territoriales y militares, estaban alimentando a un nuevo monstruo de gran magnitud que se replegó por un tiempo para tomar fuerza.

La Alemania de la posguerra contó con el apoyo económico de los Estados Unidos, que siempre, insisto, jugó el papel de neutral, esperando a que los grandes imperios se destrozaran entre sí. El capital financiero de los Estados Unidos le facilitó préstamos a Alemania y le ayudó a fortalecerse para aparecer de nuevo en escena, con mayor fuerza, beligerancia $y$ un discurso nacional-socialista que alimentaría los sentimientos de revancha del pueblo alemán como producto del Tratado de Versalles.

El monstruo acumuló fuerzas y encontró nuevos aliados. Hitler asumió el poder en Alemania en 1933 y estableció alianzas con Mussolini, que había formado su Estado fascista en Italia en 1922.

Francisco Franco, en España, desató la persecución de los comunistas y fraguó la Guerra Civil Española de 1936. Fortalecido, Hitler invadió Polonia en 1939 y ese fue el inicio de la Segunda Guerra Mundial, pero esa es otra historia.
Con su máscara de neutralidad Estados Unidos esperaba que los países en pugna durante la Segunda Guerra Mundial se desangraran entre sí y que se abortara la Revolución Bolchevique para entonces entrar al final del conflicto como los salvadores del mundo, con su ramita de olivo y su bandera de paz. Esta fue la misma estrategia utilizada para montar Gobiernos como el de Sadam Hussein, en Iraq, durante el siglo XX, crear a Bin-Laden, fortalecer su política mundial antiterrorista y apoyar el genocidio actual en Palestina.

Hay lecciones aprendidas:

1. Nunca perder la memoria histórica

2. Las causas de las guerras tienen origen económico, político, ideológico y de expansión territorial. Los pretextos sobran y se sacan de un sombrero de aprendiz de brujo.

3. Ninguna guerra es ética

4. Las guerras las hacen los poderosos para seguir siendo más poderosos, para seguir acumulando más riquezas. Los poderosos se llaman capital financiero, banqueros y dueños de las industrias militares.

5. Las hijas y los hijos de los poderosos no van a las guerras y 
no mueren en campos de batalla. En el siglo XXI las ven por tele de pantalla LED, con una Coca-Cola en una mano y una hamburguesa en la otra.

6. Los muertos los pone la clase trabajadora y los desposeídos que no tienen más capital que sus vidas.

7. Las guerras benefician a unos pocos y matan a millones. Se contratan mercenarios para participar en las guerras como en cualquier otra «empresa productiva».

8. El eufemismo daños colaterales de guerra justifica el genocidio de civiles en las guerras consideradas de "alta intensidad», si es que alguna no lo es.

9. Las mujeres, los niños y los ancianos son los más vulnerables en tiempos de guerra.

10. Los medios de comunicación nos han acostumbrado a ver la muerte como algo insignificante y que la guerra, mientras no nos afecte, no es asunto nuestro.

11. El mundo, desde la Primera Guerra Mundial, ha tenido muy pocos tiempos de paz.

12. Los organismos internacionales que deberían intervenir en los tiempos de guerra y que fueron creados después de la Segunda
Guerra Mundial son indiferentes a las guerras actuales.

¿Cuáles son nuestros retos frente a las guerras?

1. Apostar todos los esfuerzos necesarios a la paz mundial

2. Amar al prójimo como a sí mismo

3. Que las guerras no nos sean indiferentes, donde quiera que se den.

4. Es urgente la organización local, regional y mundial para protestar contra las guerras.

5. Crear frentes nacionales, regionales e internacionales contra las guerras, como lo planteó Jorge Dimitrov en 1935 frente a la amenaza nazi-fascista. Nunca tuvo mayor vigencia el pensamiento de Dimitrov como el día de hoy.

6. Educar para la paz y el respeto a la diversidad humana en un sentido amplio; respetar las diferencias de sexo, género, etnia, identidad cultural, religión, preferencias sexuales, etc.

7. Enseñar todos los días la solidaridad entre los seres humanos

Es lamentable que a cien años de una nefasta experiencia sigamos contando muertos en guerras de nada baja intensidad, utilizando tecnología de punta y matando vilmente a seres

98 La pérdida de la memoria histórica: a cien años de ... Grace Prada Ortiz 
humanos simplemente con apretar el botón de una sofisticada máquina con poder de desaparecer, en segundos, poblados enteros.

Cien años no le han bastado al ser humano para comprender que las guerras únicamente le sirven a las clases dominantes y a los señores de las guerras, mientras afectan a los sectores sociales más pobres del planeta.

Hoy presenciamos con estupor que la paz se acerca más a la utopía. Vivimos una constante pesadilla con terribles imágenes de niños muertos y pueblos arrasados por la codicia del Gobierno sionista. La muerte es la compañera de un pueblo que lucha en una guerra desigual y donde el valor de la vida es nulo. Entonces pienso: muy poco ha cambiado la humanidad desde la Primera Guerra Mundial.

La voz de las mujeres a favor de la paz debe escucharse en todos los rincones del planeta. Es tarea de cada mujer, hombre, niña, niño, anciana y anciano decir ya no más guerras. No existe otro planeta a donde ir. ¡Que cese ya el genocidio! ¡Démosle chance a las futuras generaciones de vivir y soñar con un mundo menos feo!, tal como enseñó el maestro Paulo Freire.

\section{Referencias bibliográficas}

Guerra, R. (1964). Historia de la nación cuabana. La Habana, Cuba.

Fernández Ordóñez, Rodrigo. (2014, julio) El centroamericano impasible. Enrique Gómez Carrillo, corresponsal de guerra. Revista CONTRAPODER. Disponible en: http://contrapoder. newscoop.pro/es/160/cultura/1421/ El-centroamericano-impasible-Enrique-G\%C3\%B3mez-Carrillo-corresponsal-de-guerra.htm

Lenin, V.I. (1976). Obras completas. Tomo XXX. URRS: Editorial Progreso.

Dimitrov, J. (1935). La ofensiva del facismo y las tareas de la internacional en la lucha por la unidad de la clase obrera contra el fascismo. Marxist Internet Archives. Jorge (Giorgi) Dimitrov. Disponible en: https://www.marxists.org/ espanol/dimitrov/1935.htm 